\title{
MODERN POSSIBILITIES OF DOCUMENTATION AND REPLICATION OF ARCHAEOLOGICAL FINDS
}

\author{
Karel Pavelka 1 (D), Cinzia Pappi ${ }^{2}$, Karel Pavelka jr. ${ }^{1}$ \\ ${ }^{1}$ Department of Geomatics / Czech Technical University in Prague, Faculty of Civil Engineering, Thakurova 7, Prague 6, 16629, \\ Czech Republic.pavelka@fsv.cvut.cz,karel.pavelka@hotmail.com \\ ${ }^{2}$ KFG 2615 Freie Universität Berlin, Fabeckstr. 15, 14195, Germany. cinzia.pappi@ gmail.com
}

KEY WORDS: Virtual archaeology, Digital archaeology, Laser scanning, Cultural heritage, Documentation, 3D reconstruction, Photogrammetry, SfM, 3D printing

\begin{abstract}
:
This contribution deals with the documentation of archaeological finds using close-range photogrammetry. The method of closerange photogrammetry is presented in the form of modern technology SfM (Structure from Motion), which has become very popular in the last ten years and has infiltrated a number of fields other than geodesy. Archaeological excavations and documentation of finds were carried out as part of the Iraqi / Kurdistan expedition in 2018. Photogrammetry was used experimentally to create 3D models using a conventional digital camera. The results are satisfactory, and it was possible to create copies of the findings using rapid prototyping technology (3D printing). However, processing is not entirely simple and creating a quality model is time consuming.
\end{abstract}

\section{INTRODUCTION}

Modern photogrammetric technologies have become available and used in many other fields, not only in geodesy, where photogrammetry belongs. This is linked to the development of electronics, digital cameras, a major increase in the performance of personal computers, and the development of fully automatic data processing using software. After 2000, photogrammetric technologies began to automate. Nevertheless, the basics of photogrammetry remain valid and it is necessary to follow still valid principles. Intersection photogrammetry is one of the oldest photogrammetric technologies and was used in practice at the end of the 19th century. The first person who used intersecting photogrammetry and constructed a photo theodolite was A. Laussedat in France in 1867 (Polidori, 2020). Without computers, however, this method was laborious and was soon abandoned and replaced by analogue stereophotogrammetry. After almost a hundred years, with the development of personal computers, it was put back into practice. However, only the principle remains of the original intersecting photogrammetry, while the measurements and calculations are performed completely differently. The basis is the solution of the generally known photogrammetric equation (1) using iterative methods known as bundle adjustment (Luhmann,, Robson, Kyle, \& Harley, 2006).

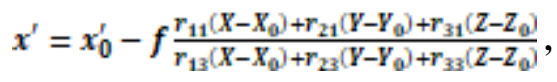

$$
y^{\prime}=y_{0}^{\prime}-f \frac{r_{12}\left(X-X_{0}\right)+r_{22}\left(Y-Y_{0}\right)+r_{32}\left(Z-Z_{0}\right)}{r_{13}\left(X-X_{0}\right)+r_{22}\left(Y-Y_{0}\right)+r_{23}\left(Z-Z_{0}\right)}
$$

where

$$
\begin{aligned}
& \mathrm{f}=\text { focal length } \\
& x^{\prime}, y^{\prime}=\text { image coordinates } \\
& x_{0}, y_{0}^{\prime} \text { coordinates of the principal point } \\
& X_{0}, Y_{0}, Z_{0}=\text { projection centre coordinates } \\
& X, Y, Z=\text { object coordinates } \\
& \mathrm{r}_{11} \ldots \mathrm{r}_{33}=\text { rotation matrix element }
\end{aligned}
$$

As early as the mid-1980s, the first systems for computer-aided intersection photogrammetry appeared; these were the Phocad Phidias or RolleiMetric CDW systems, for example (Luhmann, Robson, Kyle, \& Boehm, 2013). However, it was still necessary to measure either on film originals or on paper enlarged copies using a digitising pad with a measuring cursor. Digital cameras were available after 1990, but their resolution was too low for photogrammetry and the price was too high.

For intersecting photogrammetry with non-metric cameras, the calculation is adjusted according to (2). Unlike the historical method, there is no need to measure anything on the site (only some distance to define the scale or a set of control points for transformation to a geodetic frame). 


$$
\left(\begin{array}{c}
x^{s}-x_{0}^{s}+\Delta x^{g} \\
y^{s}-y_{0}^{s}+\Delta y^{g} \\
-f
\end{array}\right)=m \cdot \boldsymbol{R}^{T} \cdot\left(\begin{array}{c}
X-X_{0} \\
Y-Y_{0} \\
Z-Z_{0}
\end{array}\right)
$$

The equation (2) is similar to equation (1), however in (2) calculation of the geodetic $3 \mathrm{D}$ coordinates from a common digital camera is assumed, where the lens has considerable distortion.

Here $x^{\prime}, y^{\prime}$ are the image coordinates, $x_{0}^{\prime}, y_{0}^{\prime}$ are coordinates of the principal point, $f$ is the camera constant (focus distance), $\mathrm{X}, \mathrm{Y}, \mathrm{Z}$ are geodetical coordinates, $\mathrm{X}_{0}, \mathrm{Y}_{0}, \mathrm{Z}_{0}$ are the coordinates of the projection centre and $r_{11}-r_{33}$ are the rotation matrix elements. $\Delta x^{\prime}, \Delta y^{\prime}$ are the lens distortion parameters, $m$ is the scale (scalar), $\boldsymbol{R}$ is the rotation matrix.

\section{MODERN PHOTOGRAMMETRIC TECHNOLOGIES}

After the nineties, a rapid progress in the development of digital cameras occurred. Of course, digital photogrammetry needed not only a digital camera, but also specialised software for data processing. The aim of the technology was to obtain 3D spatial coordinates from the planar $2 \mathrm{D}$ coordinates of points in the image. However, this required at least two photographs of the same object taken from different positions. This is the same principle as for stereophotogrammetry. In stereophotogrammetry, for the defining of a 3D point position from images, the stereo perception is used; in intersection photogrammetry, it is necessary to get $3 \mathrm{D}$ coordinates of a measured object point, defining it by mouse clicking on this point on at least two images. There is a problem; the measured object point must be naturally or artificially signalized (like a window corner, for example, or by a special target). It is necessary for the identification of object points on different images. In contrast to stereophotogrammetry which uses parallel axes of images, it is recommended to take images with convergent axis for intersection photogrammetry.

Special software for processing digital images by intersecting photogrammetry has been very popular since the mid-1990s. After a short training, it allowed non-geodesists to use photogrammetry without knowledge of mathematical or photogrammetrical basics. Since then, there have been many original research articles that used software like PhotoModeler, Whiteness, and others, for documentation of construction or historical monuments (Kullgren, A., Lie, A. \&Tingvall, C.,1994, Pavelka, K., 2009).

At the beginning of the new millennium, with the increasing performance of personal computers, the first easy-to-use software appeared to automatically evaluate the content of images in a point cloud using image correlation, which is computationally demanding (Bundler, Agisoft PhotoScan / Metshape, Zephyr etc.), (Hůlková, M., Poloprutský, Z., Raeva, P., Matoušková, E. \& Housarová, E., 2016, Remondino, 2011).

The modern type of automatic photogrammetry for the creation of textured 3D objects has a number of names - SfM (Structure from Motion), IBMR (Image Based Modeling and Rendering), etc. Photogrammetry has spread rapidly in this form and today it competes significantly with laser scanners, especially in price. In the case of close-range photogrammetry, it is also more accurate and detailed than laser scanning. Its advantage is ease of use, mobility, and transport (Banfi, 2020).
Digital SLRs are mainly used, but simpler cameras can also be used for small jobs. Ordinary photography (with a few exceptions) is allowed in many places and usually does not require special permits, such as laser scanning or the use of drones. This is ideal for archaeological purposes, mainly for documentation of small finds, artifacts, vessels, etc. When a 3D model is created, we can make an analysis, measurements or for example, print a facsimile on a 3D printer, because it is not allowed to transport the original finds outside the country where they were found, of course.

\section{CASE STUDY}

In 2018, an international expedition to Iraqi Kurdistan (Koya district) was carried out. The aim was to prolong the archaeological excavation and research from past expeditions (2015 and 2016). The project was led by Dr. Cinzia Pappi (Pappi, 2016). During the expedition, several research and excavations were carried out. Important documentation is usually done photographically or by hand drawing. Shown here are the possibilities of 3D documentation by modern methods of photogrammetry. Within the project, drones were used to document larger areas and close-range automatic photogrammetry to document the findings. As a case project, two small artifacts were documented and virtually restored to stay for replication printing.

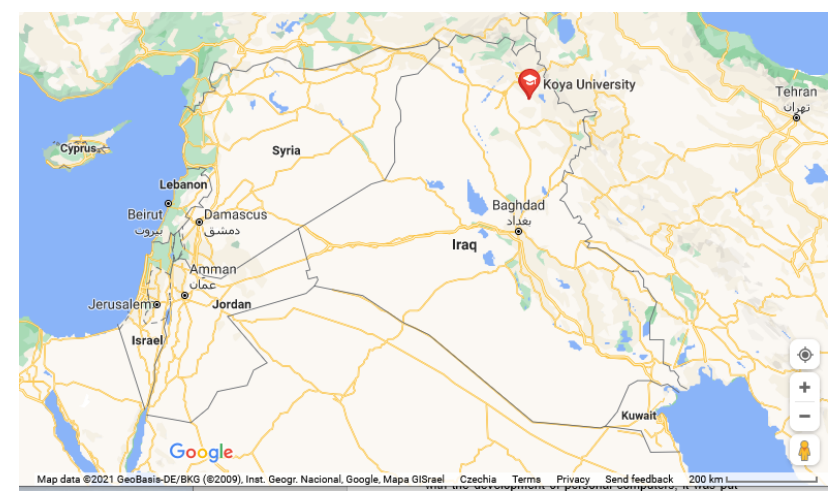

Figure 1. North Iraqi Kurdistan, Koya district

\subsection{A Glazed knobbed tile from Satu Qala (SQ 11-05)}

This fragmentary glazed tile was part of the inner wall decorations of the royal palace, built by king Assurnasirpal II (883-859 BCE) of Assyria at Idu, one of his provincial capitals, identified with the modern Satu Qala, a small village, located in Iraqi Kurdistan, $70 \mathrm{~km}$ south-east of Erbil (Pappi, 2018).

The terracotta-glazed fragment is a corner of a pillowed shaped tile, originally decorated with a central rounded knob. The knob is framed by a circular cuneiform inscription, celebrating the royal property, and by a row of black and white petals on a yellow background. The standardisation and the symmetric aspect of such objects allow reconstruction of the broken parts. The remaining space was decorated on each corner with lotus flowers and on each side with pomegranates, painted in black and white on a white background. A black and white zigzagged band frames the whole decorated surface. Such wall decorations were originally hung on the walls of specific rooms of the royal buildings of Assyria. Shape, size, and the painted decorations, all belonged to a standard repertoire, known from the royal 
residences and temples of the Assyrian capitals, i.e., Assur, the modern Qalaat, Shergaat, and Kalkhu, modern Nimrud (Nunn, 2006). Although a specific use of such objects is still debated, the common working hypothesis points to a pure decorative function (Tourte, 2013).

Not much can be said about the primary context of this object, since the fragment, originally belonging to the provincial palace dating to the $9^{\text {th }}$ century BCE, was found cut and reused in the restoration of a door socket of a private house, dating to the $6^{\text {th }}$ century BCE (Van Soldt, Pappi, Wossink, Hess, \& Ahmed, 2013).

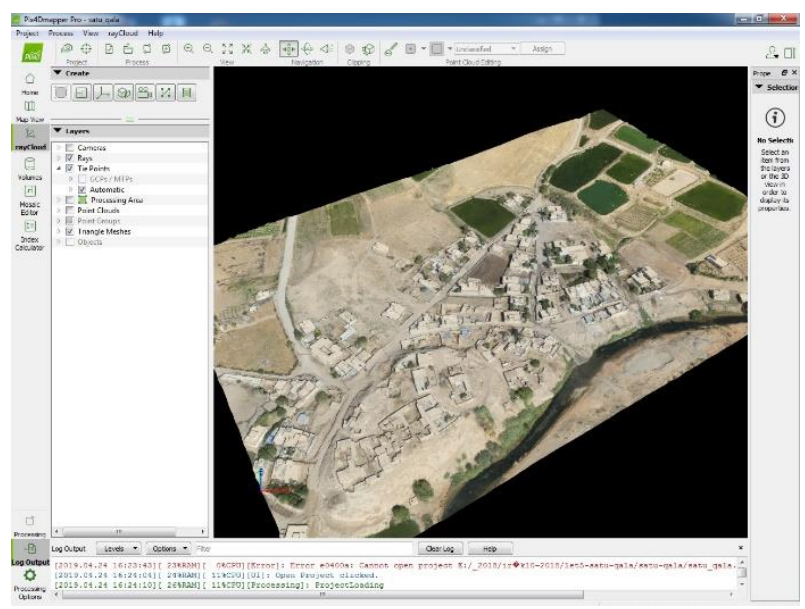

Figure 2. View of 3D model of the Satu Qala archaeologic site, eBee drone, processed in Pix4D software

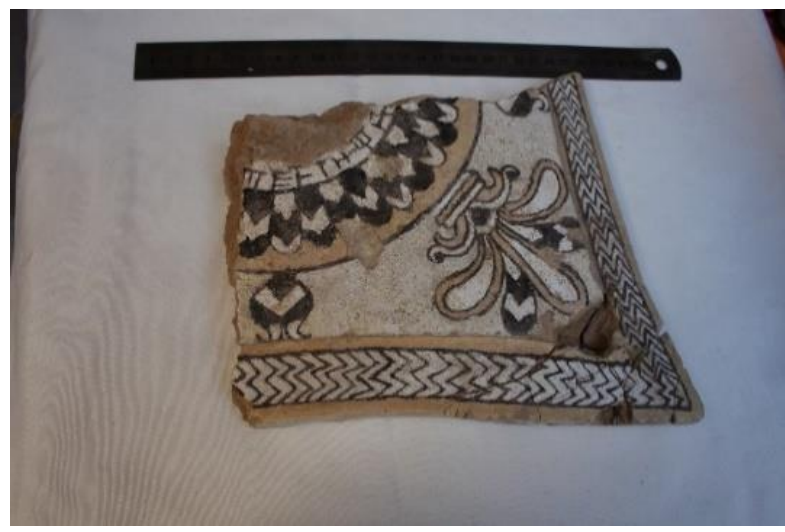

Figure 3. A gazed knobbed tile from Satu Qala

\subsection{A Bevelled Rim Bowl from Qala Shila (QSL 18.0.1001)}

This almost complete small bowl is a sporadic find from the surface of the site Qala Shila, located in the Koya plain, about $50 \mathrm{~km}$ south-east of Erbil. This roughly made ceramic vessel is a standard mass-production, dating to the $4^{\text {th }}$ millennium BCE. This type of bowl, most likely moulded or hand-made, is considered as an indicator of the cultural and economic diffusion of the Southern Uruk culture, originated in the southern Iraqi cities and diffused by the end of the $4^{\text {th }}$ millennium BCE to northern Iraq, Syria, southern Anatolia, and Iran.
These bowls, according to the archaeolmetric analysis of the clay, were most likely locally produced following the southern Mesopotamian model. The standard size and mass of production, combined with their primary archaeological contexts, suggested that the bowls were either used for the distribution of cereal rations or as bread moulds (Potts, 2009).

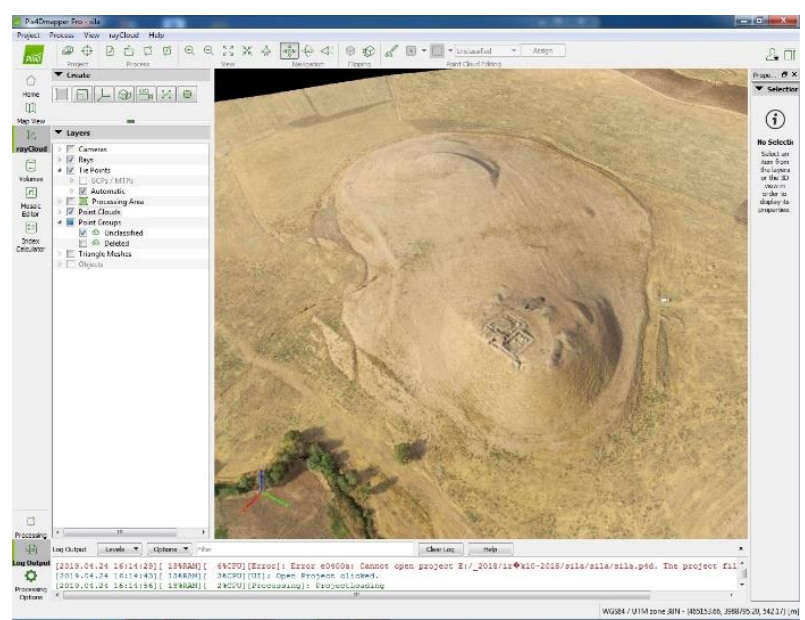

Figure 4. View of 3D model of the Qala Shila archaeologic site, eBee drone, processed in Pix4D software

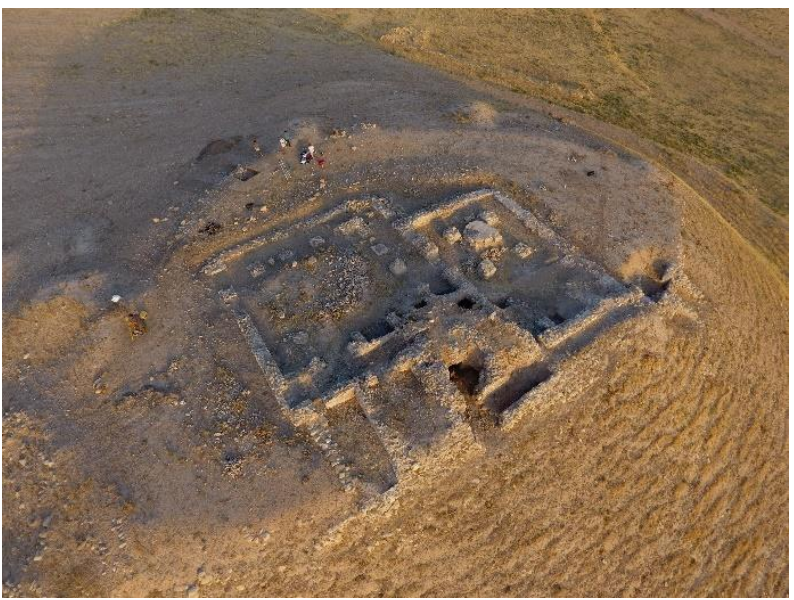

Figure 5. An aerial view of the Qala Shila archaeologic site, DJI Phantom 4 drone 


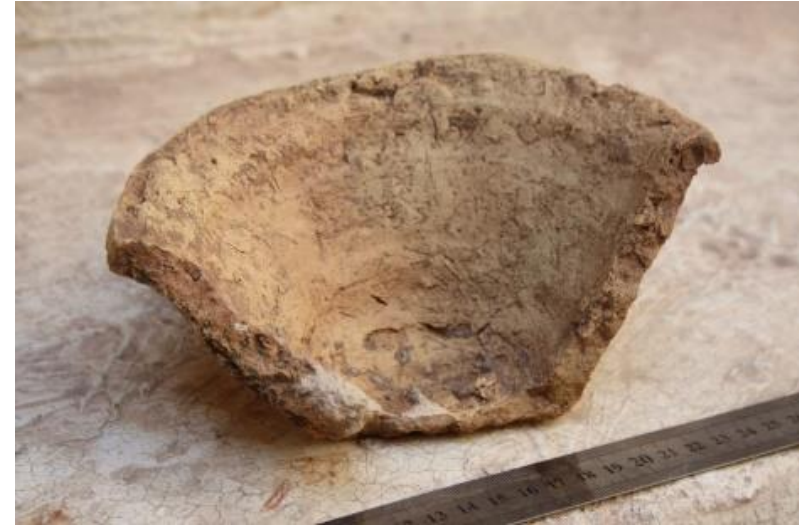

Figure 6. A bevelled-rim bowl from Qala Shila

\section{METHODOLOGY}

Photogrammetry and laser scanning of various types produce point clouds. They are further processed in special software (Fig.7).

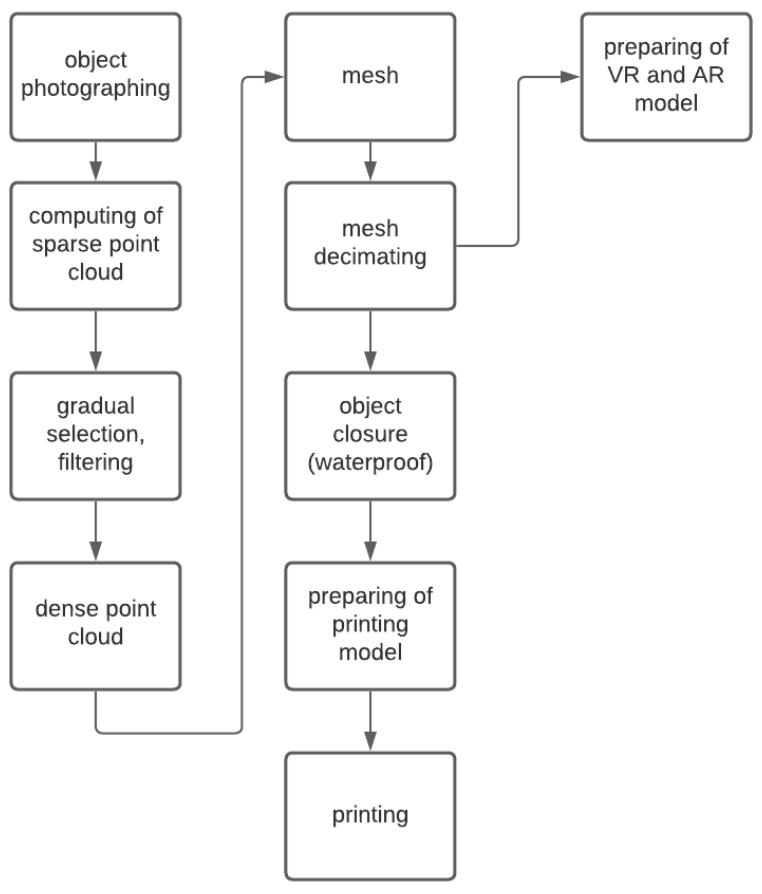

Figure 7. Data processing flowchart

\section{FINDINGS MODELLING AND RESULTS}

Both findings were photographed in detail with a Canon EOS 450D camera (55mm lens, 12MPix). A very simple method was used. A ruler was attached to the finding to adjust the scale. The object was placed on a small table and photographed around at several levels (the bowl with 112 images from above and with115 images the bowl bottom, the tile from both sides - 122, and 102 images). No special lighting was used. Image processing was performed with Metashape software. After the data analysis and first experimental processing, the photoset was divided into five parts (chunks) due to the increased model quality (complex calculation led to bifurcation of the model and considerable noise). The calculation of all sub-models went smoothly, though the final model had to be significantly cleaned of noise and surrounding points.

The models were extracted as a point cloud and exported in an interchangeable format to Geomagic Wrap software. All other adjustments were further made in this software. The bowl model was filled in accordance to the rotational shape of the find and was adapted for printing on a 3D printer. During processing, it turned out that the bowl had certain protrusions on both sides, which are not rotationally symmetrical. Another problem was found with the tile.

The models on both sides had to be joined manually (the edge was too thin) and the print was prepared for a different type of printer that also prints texture. Model adjustment took three times longer than taking photos or data processing using software. The time required for one small artefact: photography 30 minutes, image processing (depending on the computer) 1-2 hours, and model editing 3 hours.

The preparation for printing took 30 minutes but printing the model $25 \times 25 \times 25 \mathrm{~cm}$ took long hours. We tested the Stratasys F120 printer with PLA material and the Z printer 450-powder printer with the option of printing textures. The result is on figures 14-15.

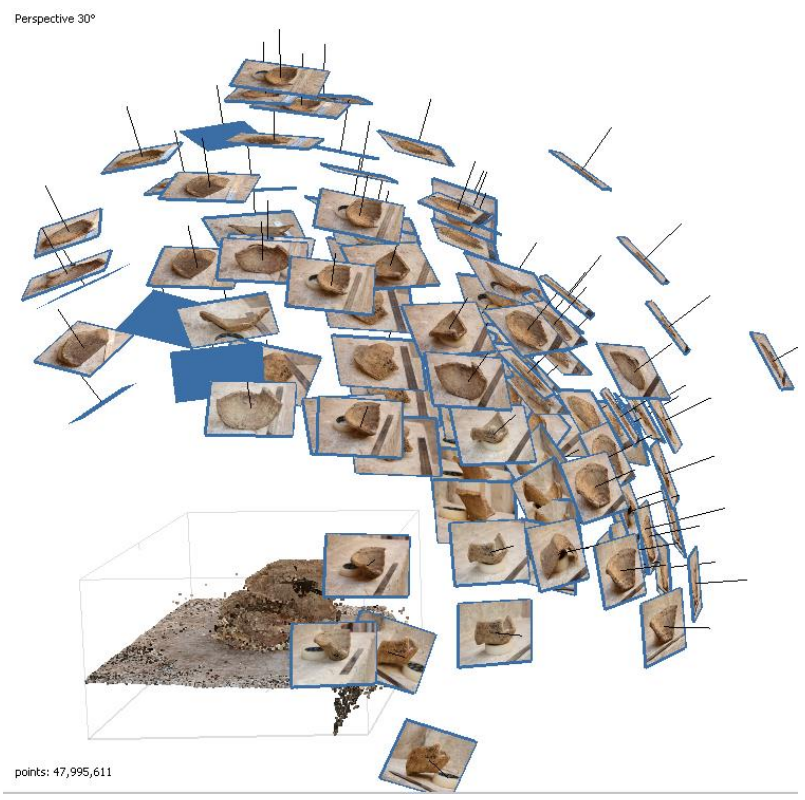

Figure 8. The point cloud from all images of the first photo-set (camera positions of all images by documentation of the bowl from Qala Shila) 

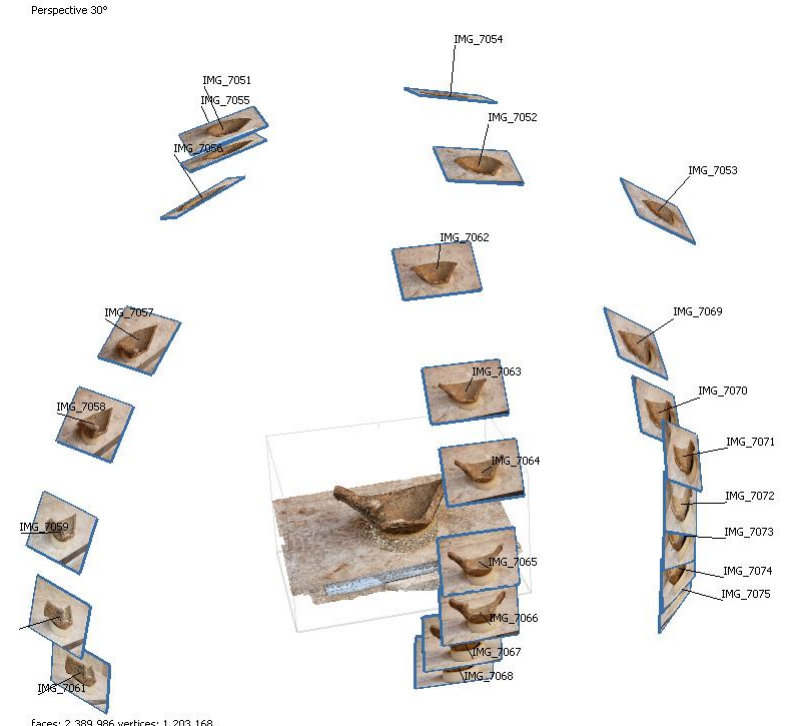

Figure 9. The camera position of separated images by documentation of the bowl from Qala Shila; processing of separated images gave better results due to reduced noise in the data (the point cloud from selected images)

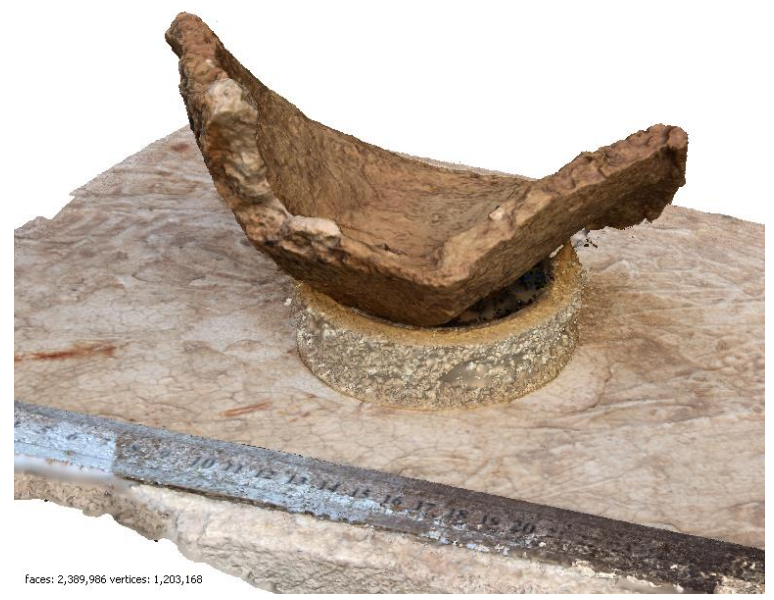

(b)

Figure 11. (a,b) Combining of all point clouds from five chunks (six millions of triangles)

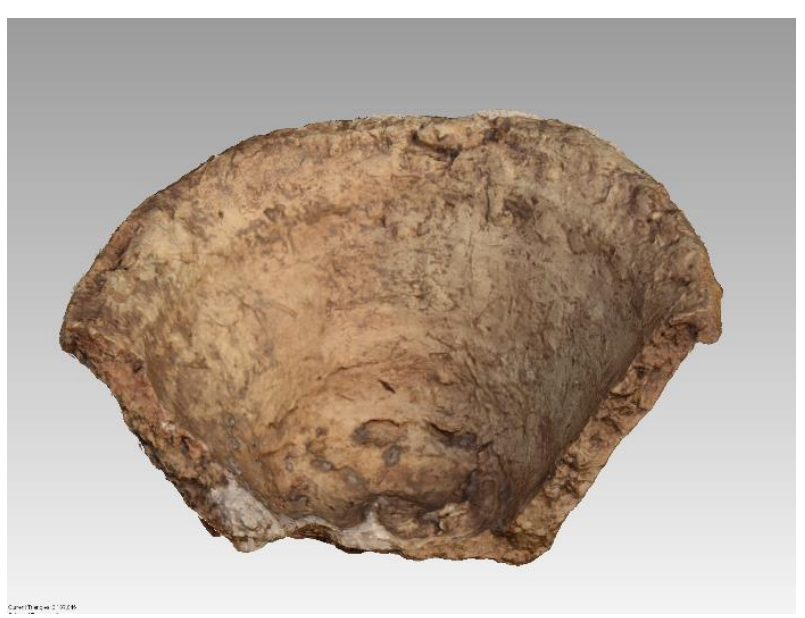

Figure 12. Creation of the final model; 3D model of the original find (the bowl from Qala Shila) 


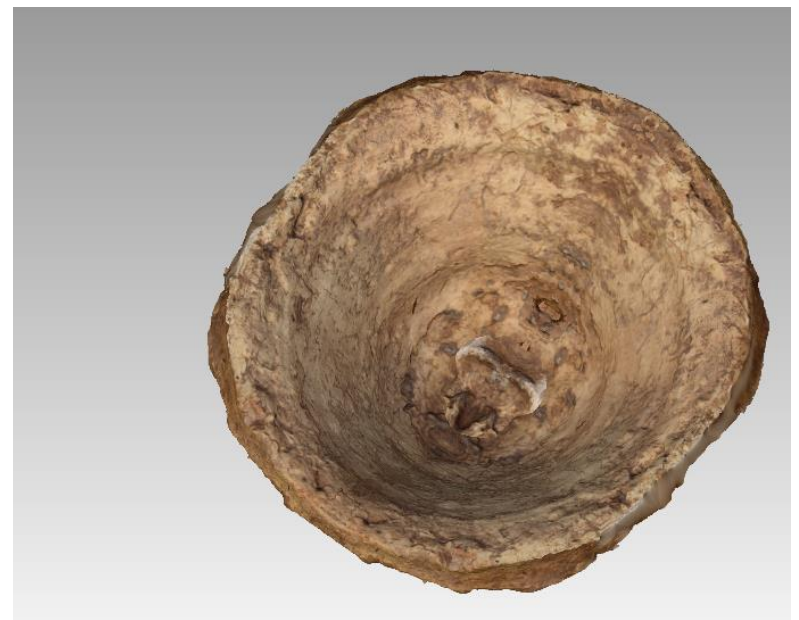

Figure 13. Creation of the final model; the assumed rotational symmetry of the finding was used (three millions of triangles)

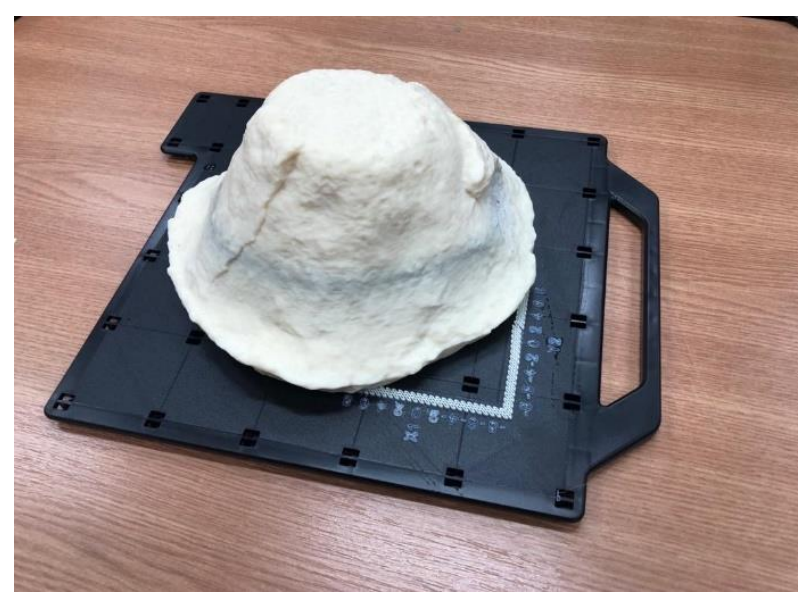

Figure 14. Rapid prototyping (3D printing) was used for the creation of the final model (the bowl from Qala Shila), 3D printer Stratasys F 120

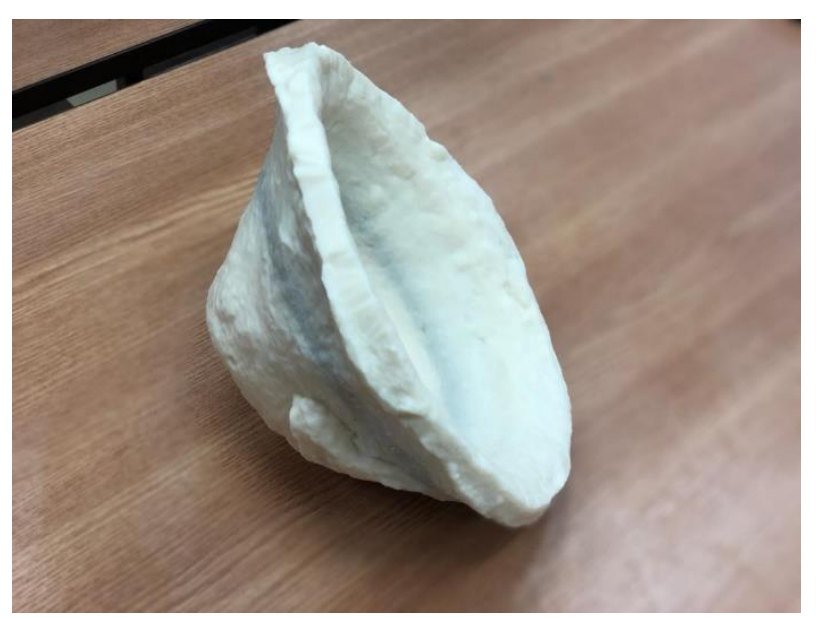

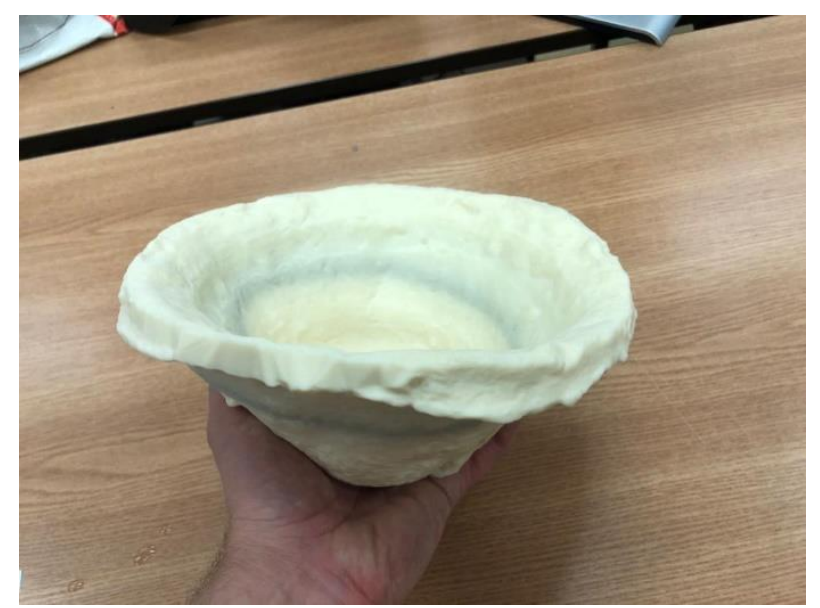

(b)

Figure 15. (a,b) Printed copy of the bowl; the missing part is completed on the basis of the assumed rotational shape (unfortunately, we did not have time to colour the printed copy)

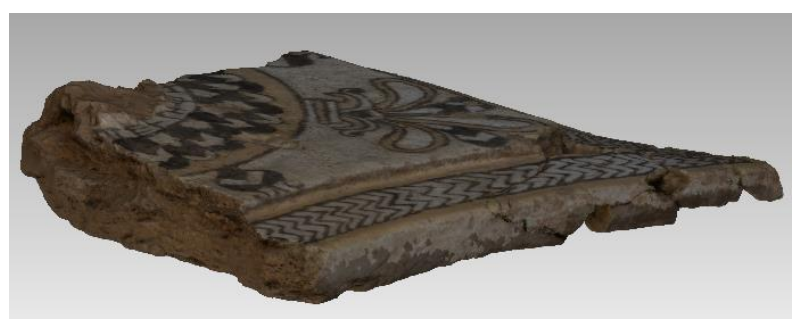

(a)

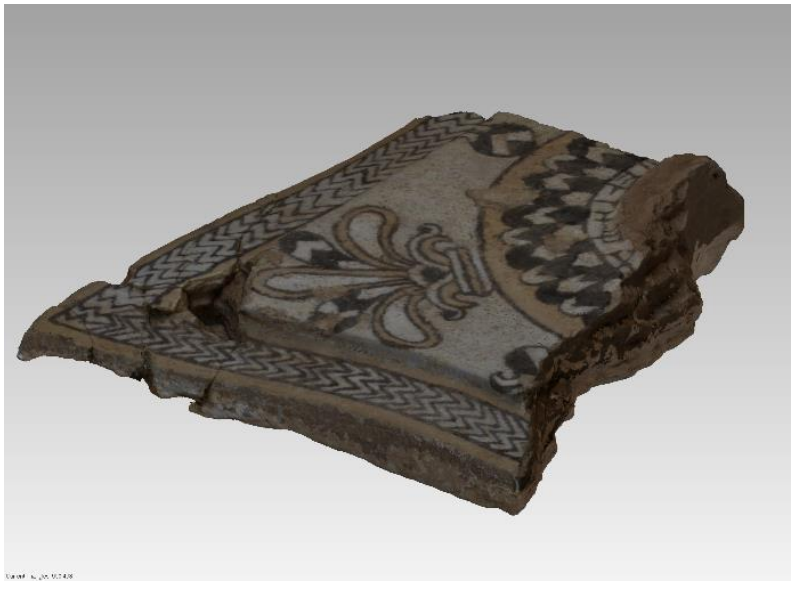

(b)

Figure 16. (a,b) The 3D model of the gazed knobbed tile (one million triangles)

(a) 


\subsection{AR and VR visualization}

Virtual (VR) and augmented reality (AR) are quite popular technologies nowadays and provide totally new possibilities of visualization for archaeological models. Virtual reality is fixed on powerful hardware and users need to have VR glasses, so for users this technology is expensive, but a VR model can be more detailed than a model in augmented reality, because it has more poly-counts than in AR, and the sense of immersion in VR is impressive. On the other side, AR technology is cheap for users, so it could be used by smartphones and tablets as a device for model visualization. Both of these technologies were used in this project. VR and AR have their own special rules and restrictions for the models that could be used with these technologies.

A high-resolution (hi-poly) model has about 6800000 polygons and needs to be decimated. A decimated model (low poly) has around 190000 polygons. After that, it is needed to generate a normal map, and thanks to these maps the final lowpoly model will look almost the same as a hi-poly model. All information about the light of bumps and dents are saved in texture, and for almost all $3 \mathrm{~d}$ software are much easier to load information from textures then millions of polygons.

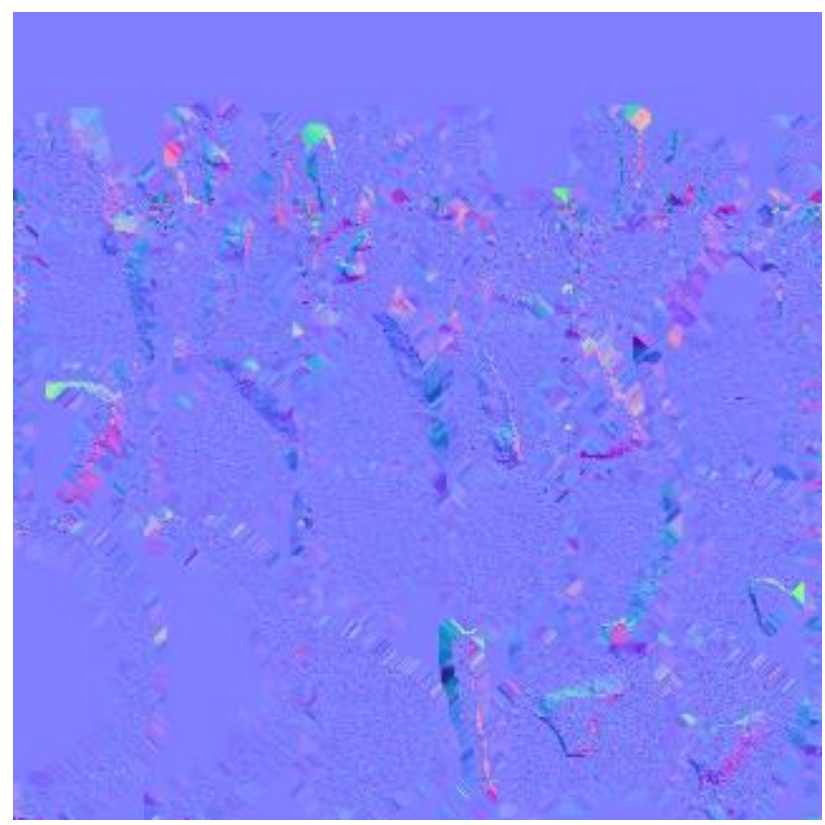

Figure 17. Normal map (left)

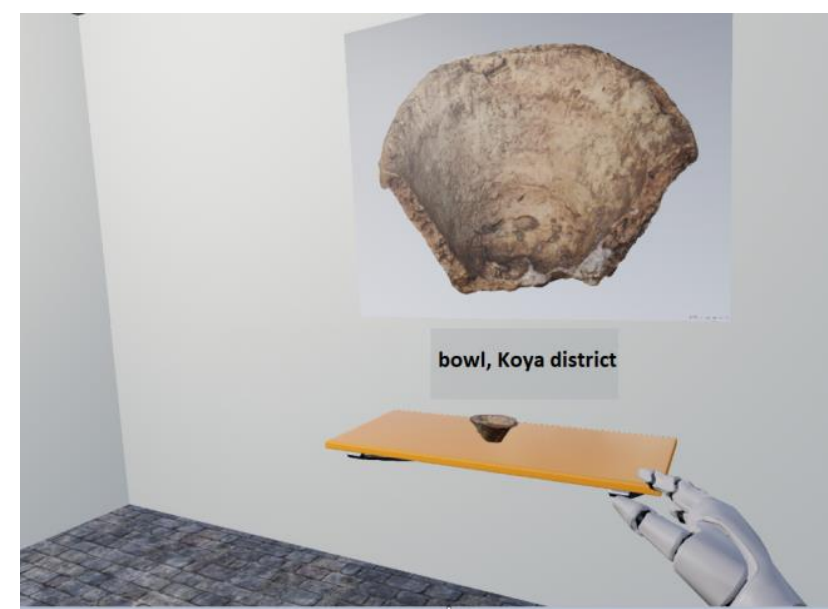

Figure 18. model placed in VR museum

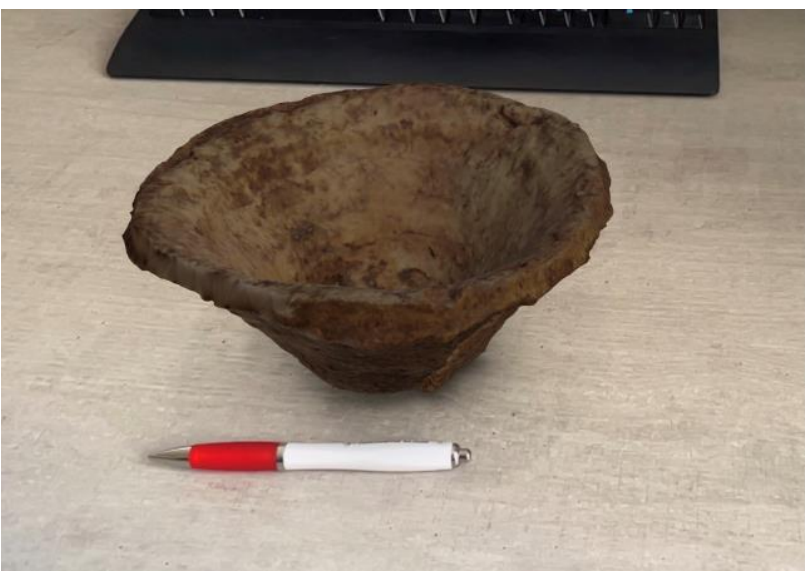

Figure 19. AR model displayed on smartphone (iOS)

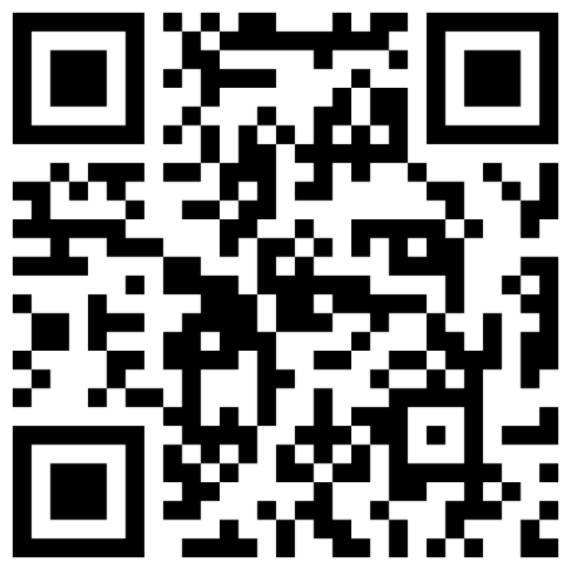

Figure 20. QR code - view model in AR (iOS devices)

All users with iOS devices can easily access a model and display it in AR after the QR code is loaded. 


\section{CONCLUSION}

Based on the results, it can be said that the close-range photogrammetry method is very suitable for modelling archaeological finds. It provides a completely objective evaluation of the findings and allows the findings to be studied virtually, sent to remote workplaces for consultation, or printed directly as a replica. On the other hand, there is a lack of input of the archaeologist's personal experience and his imagination, which can be recorded by hand drawing. In terms of speed, for smaller finds such as shards, it is still faster to draw them by an experienced person, especially profiles. Painted objects or objects with a complex structure are probably better to document photographically and possibly create small 3D models (if a set of overlapped photos was taken). Larger objects or entire archaeological sites should certainly be documented in 3D today. This enables further study and the teaching of student visualization at professional events or in a virtual museum. Virtual museums are very popular nowadays; virtual reality can be used for visiting or analysing of exhibits. The findings can thus be presented to the public. Here, the benefit of $3 \mathrm{D}$ documentation is completely logical. The question is, of course, the possibility of archiving. Drawings in a workbook last a long time, while a CD, DVD, flash drive, or portable disk may be lost or may not be readable over time.

\section{ACKNOWLEDGEMENTS}

'This work was supported by the [internal grant of the Czech Technical University in Prague] under Grant [number SGS21/054/OHK1/1T/11].

\section{REFERENCES}

Banfi, F., 2020. HBIM, 3D drawing and virtual reality for archaeological sites and ancient ruins. Virtual Archaeology Review, 11(23), 16-33. https://doi.org/10.4995/var.2020.12416

Hůlková, M., Poloprutský, Z., Raeva, P., Matoušková, E, Housarová, E., 2016. Complex Analysis and Documentation of Historical Buildings Using New Geomatics Methods, The Civil Engineering Journal, 2016(4), 1-8. ISSN 1805-2576. https://doi.org/10.14311/CEJ.2016.04.0027

Kullgren, A., Lie, A., Tingvall, C., 1994. Photogrammetry for documentation of vehicle deformations-A tool in a system for advanced accident data collection, Accident Analysis \& Prevention, Volume 26, Issue 1,pp. 99-106, ISSN 0001-4575, https://doi.org/10.1016/0001-4575(94)90072-8.

Luhmann, T., Robson, S., Kyle, S., Harley, I.A., 2006. Close Range Photogrammetry: Principles, Techniques and Applications. ISBN: 9780470106334

Luhmann, T., Robson, S., Kyle, S, Boehm, J., 2013. CloseRange Photogrammetry and 3D Imaging. Walter de Gruyter, p. 702

Nunn, A., 2006. Knaufplatten und Knäufe aus Assur (WVDOG 112), Harrassowitz Verlag. ISBN

978-3-447-05504-8, p.224

Pavelka, K., 2009. Detailed documentation and 3D model creation of Dalal Bridge using terrestrial photogrammetry in
Zakhu, northern Iraqi Kurdistan, Proceedings of 22nd CIPA Symposium. Kyoto, pp. 325-331.

Pappi, C., 2016. Satu Qala: An Assessment of the Stratigraphy of the Site in the Archaeology of the Kurdistan Region of Iraq and Adjacent Regions, Edited by K. Kopanias and J. MacGinnis. Archaeopress Publishing Ltd.Gordon House, 276 Banbury Road,Oxford OX2 7ED, ISBN 978178491393 9, pp.297-308

Pappi, C., 2018. The Land of Idu: City, Province, or Kingdom? State Archives of Assyria Bulletin 24, pp. 97-123).

Polidori, L., 2020. On Laussedat's Contribution to the Emergence of Photogrammetry. ISPRS - International Archives of the Photogrammetry, Remote Sensing and Spatial Information Sciences. XLIII-B2-2020. 893-899. https://doi.org/10.5194/isprs-archives-XLIII-B2-2020-893-2020 Potts, D. (2009). Bevel-Rim Bowls, and Bakeries: Evidence and Explanations from Iran and the Indo-Iranian Borderlands. Journal of Cuneiform Studies 61, pp.1-23.

Remondino, F,.2011. Heritage Recording and 3D Modeling with Photogrammetry and 3D Scanning. Remote Sensing. 3. 1104-1138. https://doi.org/10.3390/rs3061104

Tourte, F., 2013. Distribution, Materials and Functions of the "Wall Knobs" in the Near Eastern Late Bronze Age: from South-Western Iran to the Middle Euphrates, in Susa and Elam. Archaeological, Philological, Historical and Geographical perspectives, ed. by K. de Graef and J. Tavernier; pp. 173-190

Van Soldt, H. W., Pappi, C., Wossink, A., Hess, C.W., Ahmed, K.M., 2013. Satu Qala: A Preliminary Report on the season 2010-2011, Anatolica, 39, pp. 197-239 